\title{
RELACIONES Y ESTRATEGIAS DE EXPANSIÓN INCA EN EL NOROESTE ARGENTINO: MARCADORES GRÁFICOS E INDICADORES MATERIALES EN LAS QUEBRADAS ALTAS DEL VALLE CALCHAQUÍ1
}

\author{
INCA RELATIONS AND EXPANSION STRATEGIES IN NORTH-EAST ARGENTINA: \\ GRAPHIC MARKERS AND MATERIAL INDICATORS IN THE HIGH GORGES OF \\ THE CALCHAQUI VALLEY
}

\author{
Verónica Isabel Williams ${ }^{2}$ y María Cecilia Castellanos ${ }^{2}$
}

\begin{abstract}
Para el Valle Calchaquí medio, en el noroeste de Argentina, se ha postulado la implementación de diferentes estrategias de apropiación del paisaje por parte del Estado inca, las cuales variaron según las condiciones locales, ambientales y demográficas. Una de las estrategias apunta a una modalidad directa consistente en la intervención en infraestructura agrícola en sectores sin evidencia de asentamientos locales tanto habitacionales como defensivos del tipo pukara, muy populares en el área de estudio para el período de Desarrollos Regionales (PDR) o período Intermedio Tardío (PIT), que podrían haberse convertido en verdaderos enclaves productivos; y otra, de corte más simbólico, sugiere la apropiación estatal de lugares con historia previa, donde los pukaras, funcionaron como hitos territoriales, asociados a una forma de habitar el espacio entramando múltiples prácticas y actuando como referentes de memoria colectiva. En este artículo discutimos la posibilidad del despliegue de estrategias y ceremonias rituales como expresión de la demarcación territorial y anexión a la política Inca en áreas agrícolas de valles y quebradas altas del Calchaquí, tomando en cuenta el concepto de Capacocha.
\end{abstract}

Palabras claves: Valle Calchaquí, anexión territorial inca, marcadores gráficos, campos agrícolas, Capacocha.

It has been suggested that, depending on local, environmental, and demographic conditions, the Inca state implemented diverse strategies of landscape appropriation in the middle Calchaqui Valley, Northwest Argentina..One of the direct strategies consisted in the intervention of agricultural infrastructure in areas with no evidence of either local habitational or pukarastyle defensive settlements, which were very popular in the study area during the Regional Development Period (RDP) or Late Intermediate Period (LIP) and which could have become true Inca productive enclaves. Another strategy, of a more symbolic character, suggests that the Inca state appropriated places with a previous history, and that the pukaras acted as territorial milestones associated to a way of occupying the space, interweaving numerous practices and acting as referents of collective memory. In this article, we discuss the possibility that the strategies and ritual ceremonies were used as an expression of the territorial demarcation and annexation to the Inca policy in agricultural areas of the valleys and high gorges of Calchaqui, taking into account the concept of Capacocha.

Key words: Calchaquí Valley, Inca territorial annexation, graphic markers, agricultural fields, Capacocha.

Diversos investigadores remarcaron la heterogeneidad y versatilidad de la expansión inca en sectores alejados del Cusco como, por ejemplo, el Noroeste Argentino -en adelante NOA- (Acuto 1999; de Hoyos 2011; González y Tarragó 2005; Williams et al. 2009, entre otros).

La incorporación de territorios y poblaciones a la política estatal varió regionalmente y las estrategias empleadas debieron ajustarse a las condiciones sociopolíticas y naturales de cada zona (Mulvany
2003; Santoro et al. 2010). Específicamente para el NOA se ha sugerido una variedad de estrategias que incluyen el conflicto, la diplomacia y una negociada articulación pacífica, la conquista ritual y la incorporación de nuevos símbolos y significados, todas no excluyentes (Acuto 1999; de Hoyos 2011; González y Tarragó 2005; Lorandi 1988; Nielsen y Walker 1999; Williams et al. 2009). Una hipótesis sostiene que aquí se habría dado una lógica de ocupación estatal en bolsones o islas en

\footnotetext{
${ }^{1}$ Una primera versión de este trabajo fue presentada en el Qhapaq Ñan II, Taller Internacional en torno al Sistema Vial Inkaico (24-27 de octubre de 2017), efectuado en Salta, Argentina. Este manuscrito fue evaluado por pares externos y editado por el Comité Editorial de Chungara y los editores invitados Carlos González y Christian Vitry.

${ }^{2}$ Instituto de las Culturas (IDECU), Universidad de Buenos Aires-CONICET, Buenos Aires, Argentina. veronicaw33@yahoo.com; cecicastellan88@yahoo.com.ar
} 
áreas productivas y estratégicamente ubicadas (Williams y D'Altroy 1998). Dicha estrategia habría implicado el desarrollo de dos sistemas de control (hegemónico y territorial), administrados desde el Cusco y desarrollados en función de las alianzas con los jefes étnicos locales (Williams et al. 2009). Otra estrategia que se ha planteado es el reclamo simbólico del paisaje a partir de la resignificación de lugares y espacios sagrados como montañas, cerros, lagunas, cuevas, etc. (Ceruti 2003; Olivera 1991; entre otros).

Los intereses de la expansión incaica hacia el NOA pudieron ser tanto la necesidad de la obtención de minerales (Raffino 1981) como el aprovechamiento de mano de obra para la producción minerometalúrgica y agrícola para sostener el sistema, a partir de las prestaciones rotativas (González 2010; Mulvany 2003). Aunque se ha señalado que en este sector del Collasuyu no se logró someter a todas las poblaciones de la región al sistema de prestaciones establecido por los incas (Lorandi 1988).

Indudablemente uno de los elementos fundamentales para la expansión estatal fue la construcción y/o reutilización de caminos, un símbolo de poder y autoridad del estado y un marcador espacial en la territorialidad simbólica estatal, como propone Berenguer (2001). A lo largo del camino se establecieron enclaves administrativos y productivos (chakras), tambos y fortalezas (Raffino 1981; Vitry 2000); asociados a hitos demarcatorios, sayhuas, apachetas u otras manifestaciones de carácter logístico o ritual (¿Capacochas?) que, en conjunto, daban cuenta de la organización y el control de territorios (Hyslop 1984; Sanhueza 2004; Vitry 2000, entre otros). Pero a su vez, esta construcción de un nuevo paisaje inca en territorios que eran anexados dirigía la atención hacia la configuración de una memoria y un vínculo con un paisaje, un pasado y un relato institucionalizado, pero no lineal, que se adecuaba a las historias locales (Kosiba 2015).

La importancia y el papel del sistema vial dentro de la política expansiva Inca, el proceso de configuración de paisajes y la consolidación de un nuevo orden geopolítico ha sido remarcada a partir de diversas investigaciones; donde fue fundamental la demarcación de caminos e infraestructura vial como una de las principales obras que integraba diferentes concepciones del mundo a la nueva esfera política, económica, simbólica y ritual (Vitry 2017). Bajo esta cartografía sagrada, un elemento de suma importancia son las geoformas destacadas, como por ejemplo las montañas, que han sido definidas como geosímbolos de referencia (sensu Bonnemaison 1992; en Vitry
2017:42). Esto refuerza la necesidad de abordar el estudio e interpretación de la vialidad inca desde un enfoque de carácter holístico que considere el paisaje circundante y las múltiples significaciones que conforman un entramado de narraciones, cartografías e infraestructura asociadas.

En este trabajo analizamos algunas propuestas que nos permiten reflexionar sobre las estrategias de expansión estatal que pudieron haberse aplicado por el Estado en las quebradas altas del sector medio del Valle Calchaquí (actual provincia de Salta, Argentina) considerando datos brindados por la arqueología. Una variable que interesa destacar es la agricultura. Respecto a este tema, trabajos como los de Albeck (2016), Korstanje et al. (2010), entre otros, destacan la agricultura y su relación directa con las políticas estatales en el extremo norte de Argentina. Dichos aportes permitieron diferenciar áreas agrícolas y áreas minero-metalúrgicas asociadas al camino. Albeck propone que, en algunos casos, las áreas productivas agrícolas servían a la logística del camino mientras que en otros el camino se encontraba al servicio de las áreas productivas, como los grandes bolsones de producción agrícola de Puna y quebrada (Albeck 2016:61).

Para trabajar la marcación dentro de las hipótesis de expansión inca consideramos las propuestas de Gentile (2013), Hayashida (2018) y Rostworowski (2003), tomando a manera de hipótesis la noción de capacocha y sus posibles manifestaciones asociadas a la ocupación territorial en relación con las áreas productivas agrícolas y/o mineras, a lo que sumamos datos e información producto de los estudios que se vienen desarrollando en los últimos 10 años en el sector medio del Valle Calchaquí. Estos antecedentes nos permiten reflexionar sobre el proceso de expansión estatal que se habría dado en valles altos del NOA y plantear interrogantes desde las materialidades y los contextos de asociación vinculadas a la anexión y marcación territorial incaica en este sector del Collasuyu.

\section{El Valle Calchaquí y la Administración Inca}

En el marco de la organización estatal se planteó el establecimiento de cinco grandes provincias o wamani en el actual territorio argentino (González 1982). Para el área que nos interesa en este trabajo, se ha sugerido la conformación de la provincia de Chicoana, con su posible cabecera en La Paya (González 1982). Las propuestas etnohistóricas, bajo la hipótesis del conflicto, han señalado las dificultades de la anexión del territorio Calchaquí a la administración estatal (Lorandi 1988). 
Por su parte, los estudios arqueológicos realizados observaron que en el norte del valle los sitios incas se encuentran ubicados en los dos tramos principales del camino, en puntos estratégicos que permiten conectar el valle con la puna, las quebradas del Toro y de Humahuaca. Una de las propuestas es que los incas se establecieron en este sector en espacios donde no había ocupación local previa construyendo asentamientos multifuncionales como Cortaderas y Potrero de Payogasta, los cuales ejercían un control de tipo territorial (Williams et al. 2009). Además, asociados a estos grandes establecimientos, sobre una ruta que lleva a la Quebrada del Toro, se emplazaron una serie de tambos (Hyslop 1984; Vitry 2000).

En el Valle Calchaquí norte se han identificado asentamientos de factura netamente incaica y posible función administrativa como Cortaderas y Potrero de Payogasta, otros con componentes incaicos ubicados a lo largo del tramo occidental del camino y sitios que cuentan con ocupaciones locales e inca como La Paya y Guitián (Acuto 1999; Williams y D'Altroy 1998). Este paisaje heterogéneo ha llevado a proponer diversas estrategias de ocupación del territorio Calchaquí por parte del Estado inca, que implicaron un control de tipo indirecto o hegemónico y otro de tipo directo o territorial (D'Altroy 2003; Williams et al. 2009). Otra modalidad habría estado asociada con la distribución de restos muebles incaicos, como piezas cerámicas y objetos de metal registrados, por ejemplo, en sitios locales como Tero y Fuerte Alto en los alrededores del actual pueblo de Cachi, y Valdez sobre la margen oriental del Valle Calchaquí (Acuto 1999:149). En los últimos años se ha planteado también que los incas habrían intervenido en el norte del valle a partir del empoderamiento y la vinculación de algunos grupos locales con la esfera estatal, posibilitando la diferenciación de ciertos grupos y produciendo un nuevo tipo de agencia (Acuto 2011).

A diferencia de lo planteado para el Valle Calchaquí, en sectores aledaños hacia el este, como Amblayo y el Valle del Cajón al Sur, las instalaciones más grandes fueron emplazadas en áreas abiertas, expuestas, sin protección natural ni construcciones defensivas (de Hoyos 2011). Esto podría indicar que los incas ejercieron un control geopolítico directo y efectivo de ambos valles, lo que permitió contar con caminos alternativos a aquellos tradicionalmente considerados principales (Raffino 1981). Para el valle de Yocavil, hacia el sur del Calchaquí, las evidencias muestran una ocupación un poco más intensiva en el extremo sur y solo algunos conjuntos constructivos discretos en algunos sectores del valle (González y Tarragó 2004, 2005). Esta situación ha llevado a explicar, desde la hipótesis de la diplomacia, la discreta presencia inca en el Valle de Santa María, y la importante expansión iconográfica con la popularidad del motivo escutiforme, sucedida en estos momentos (de Hoyos 2011).

\section{Los Valles Altos del Sector Medio del Valle Calchaquí durante el Período de Desarrollos Regionales (PDR) o PIT y la Expansión Incaica}

En el sector medio del Valle Calchaquí los asentamientos prehispánicos del tipo conglomerado se habrían iniciado hacia los siglos IX-X DC, como se observa en el sitio Molinos 1 (Baldini 2003). Para momentos posteriores, se propone una concentración poblacional sobre el valle principal y algo distinto hacia el interior de las quebradas altas, entre los 2.600 y $3.400 \mathrm{msm}$, en el cual habría predominado un modo de asentamiento de carácter rural, al que se asocian escasos poblados concentrados y de carácter defensivo tipo pukara (Baldini y Villamayor 2007:37; Williams 2015). Al interior de estas quebradas, hasta el momento, se han localizado alrededor de 25 sitios habitacionales, entre ellos nueve pukaras, y algunos conjuntos arquitectónicos pequeños que no pasan las 2 ha (Villegas 2014; Williams 2015). Los pukara se distribuyen en una superficie de $149 \mathrm{ha}\left(1,49 \mathrm{~km}^{2}\right)$ y se emplazan en lugares estratégicos, con muy buena visibilidad, asociados a espacios de tránsito y a asentamientos agrícolas (Villegas 2014) (Figura 1). Esta posición también pudo haber estado vinculada con el control de tránsito y la interacción entre ambientes o pisos altitudinales; como por ejemplo hacia la puna, donde se localizó un ofrendatorio de altura (Rebitsch 1966) ${ }^{1}$.

La cronología disponible para los sitios tipo pukara y agrícolas permiten sugerir una ocupación que se extendería desde los inicios del PDR o PIT (ca. 900 a 1400 DC) hasta, por lo menos, mediados del siglo XVII cuando toman protagonismo los pukara en las narrativas históricas sobre los levantamientos indígenas del Valle Calchaquí (Williams 2015) (Tabla 1).

La presencia inca en el Valle Calchaquí medio se hace evidente a través del emplazamiento de seis asentamientos con arquitectura de filiación inca tanto en el valle troncal del Río Calchaquí como en el piso de puna (Villegas 2014; Williams 2015; Williams et al. 2010). Una característica para remarcar es que en las quebradas altas los sitios estatales se encuentran separados de los asentamientos locales, en lugares altamente visibles desde distintos puntos 




Figura 1. Sitios arqueológicos del período de Desarrollos Regionales o período Intermedio Tardío e Inca registrados en las quebradas altas del Calchaquí Medio. Modificado de Villegas (2014:37).

Archaeological sites of the Regional Development Period or Late Intermediate Period and Inca Period recorded in the high gorges of the Middle Calchaquí. Modified by Villegas (2014:37).

y estratégicamente ubicados, observando una lógica de localización entre lo local y lo inca y un paisaje diferente al del PDR o PIT (Villegas 2014; Williams 2015). El sitio estatal de mayor envergadura en el sector es el Pukara de Angastaco a $1.862 \mathrm{msm}$, sobre la margen derecha del Río Calchaquí y a la vera del camino inca que corre en sentido norte-sur (actual Ruta 40) (Figura 2). Este pukara pudo haber constituido una defensa contra poblaciones locales hostiles como un recordatorio constante de la presencia y poderío inca (Williams et al. 2005). El mismo presenta una planta subcuadrangular que comprende 4,5 ha y se halla rodeado por una muralla perimetral con bastiones cuadrangulares (Raffino y Baldini 1983; Williams et al. 2005). Asociado a este sitio se encuentra un conjunto arquitectónico interpretado como un tambo, conservando solo un par de estructuras rectangulares (Williams 2015; Williams et al. 2005). Desde el Pukara de Angastaco se observa gran parte del valle del Río Calchaquí, tanto hacia el norte como hacia el sur, así como el primer tramo de la Quebrada de Angastaco, vía de comunicación hacia la puna en cuyo recorrido se transita por los pukara de Tacuil, Peña Punta y Gualfín, correspondientes al PDR (Figura 2).

Se destacan también, grandes extensiones agrícolas como Corralito, Mayuco y la Campana, cuyas características constructivas han llevado a proponer el desarrollo de estrategias de maximización de la producción y administración de bienes y servicios a través del dominio del espacio productivo (Williams et al. 2010:202).

Esta información respondería a un control estatal directo en la zona, con una ocupación segregada de los asentamientos locales, situación compartida con el valle del Río Potrero en el Calchaquí Norte, los valles meridionales, como Santa María, y sur de la Quebrada de Humahuaca (D’Altroy et al. 2000). 


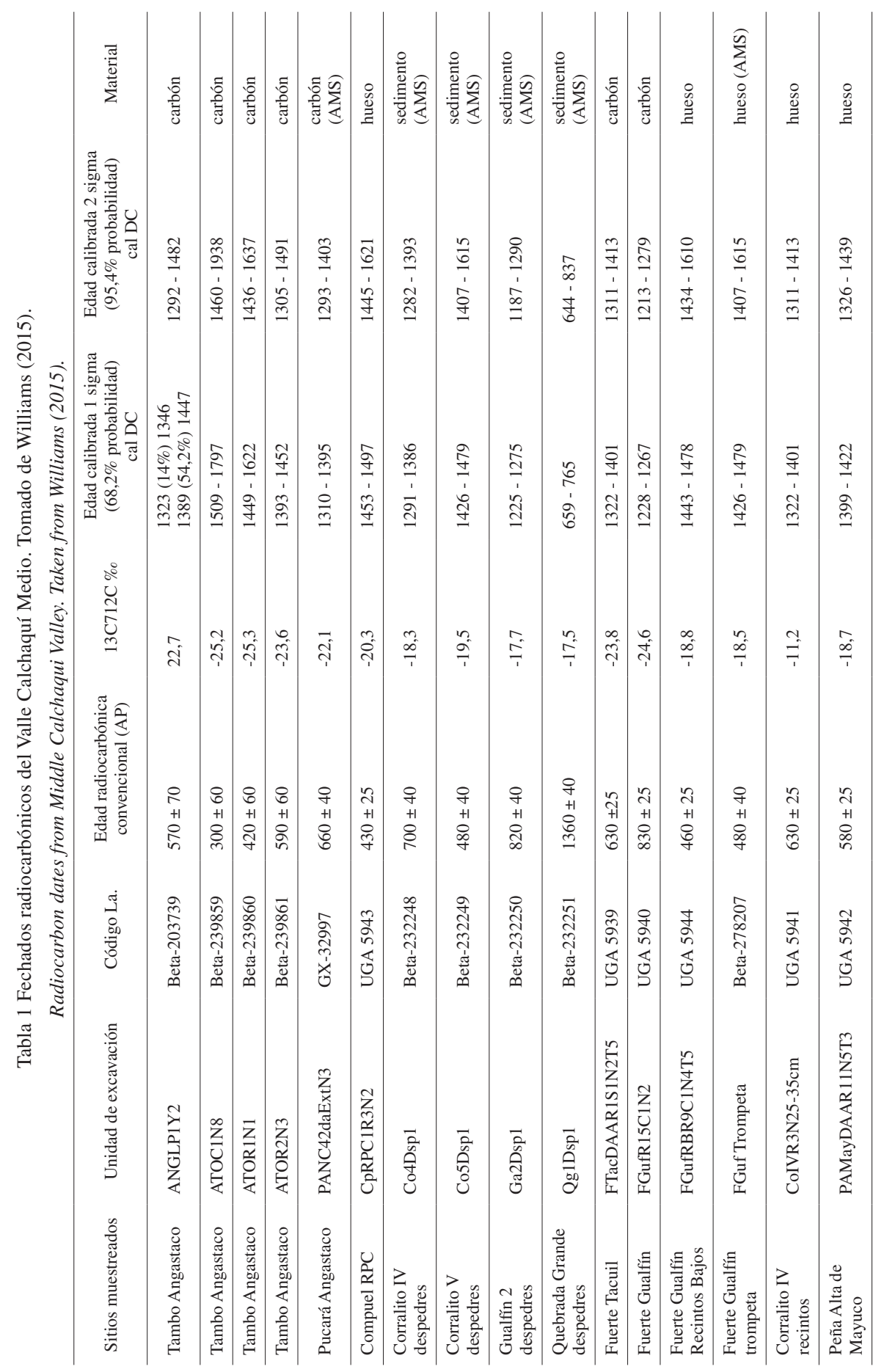




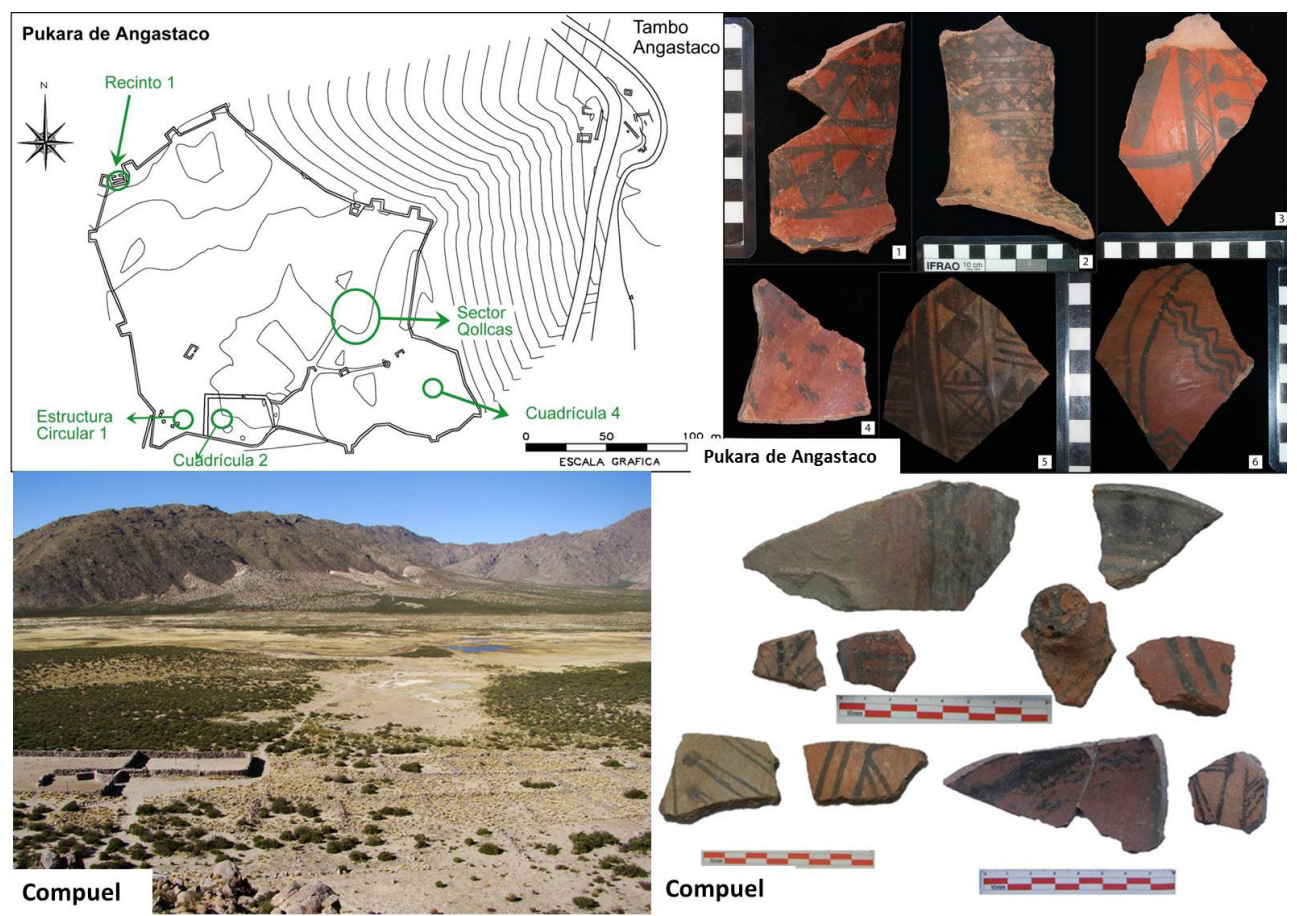

Figura 2. Arriba: plano del sitio inca Pukara de Angastaco (elaborado por M. Mariani) y cerámica inca recuperada en el sitio (fotografías de V. Williams). Abajo: Vista general de Compuel (fotografía de V. Williams) y cerámica recuperada en el sitio (fotografías de C. Castellanos).

Above: map of the Pukara de Angastaco Inca site (courtesy of M. Mariani) and Inca ceramics recovered on the site (photographs by V. Williams). Below: General view of Compuel (photographs by V. Williams) and ceramics recovered on the site (photographs by C. Castellanos).

Otros asentamientos que presentan arquitectura de trazado inca en la zona son Amaicha II (Raffino y Baldini 1983), los sitios tipo celdas u ortogonales ${ }^{2}$ de Gualfín 1 y 2 en el sector alto de la quebrada del Río Gualfín y el sitio de Compuel, ubicado en piso de puna, a $3.384 \mathrm{msm}$. A este último se llega por un camino al cual se accede desde el este (Gualfín) y que posiblemente sea un tramo de camino antiguo (inca o anterior) que se continúa con el camino que une Tambo Gualfín ${ }^{3}$ con Pukara de Angastaco, ambos sitios inca (Villegas 2014; Williams y Villegas 2017). En Compuel se destacan inmensas estructuras ortogonales o de tipo celdas (de Hoyos y Williams 2017), una kancha y un pequeño sitio habitacional (Figura 2). La localización estratégica de Compuel lo posiciona en el cruce de caminos que comunican zonas como el sector sur del Salar de Atacama o el Alto Loa, la puna catamarqueña y los valles mesotermales de Angastaco-Molinos (Williams y Villegas 2017). Este sitio se localiza en un punto de ingreso al espacio puneño donde se emplazan volcanes, montañas o apus que albergan santuarios y ofrendatorios y sitios estatales como Cerro Galán (5.650 msm), la Tambería de Diamante
(4.500 msm), Volcán Peinado (5.741 msm), Volcán Antofalla (6.440 msm), Cerro Tebenquiche (5.838 $\mathrm{msm})$ y Volcán Carachipampa (5.486 msm) en la zona del Salar del Hombre Muerto. Desde Compuel se llega a Jasimaná hacia el suroeste vinculándose con el Cerro Chuscha ${ }^{4}(5.412 \mathrm{msm})$, donde se localizó un posible contexto de Capacocha, y el Valle del Cajón que concentra la mayor cantidad de construcciones ortogonales o tipo celdas, como Corral Negro, San Antonio del Cajón, La Maravilla, Campo de Huasamayo, La Lagunita y Percal (de Hoyos y Williams 2017).

Todos los sitios arriba mencionados se encuentran vinculados por vialidad en algunos tramos de caminería con componentes incas, que corresponden a los tipos empedrado (Compuel), despejado (Tambo Gualfín), con talud y muro de contención (Angastaco-Pucará, Gualfín, Corralito) (Williams y Villegas 2017), que conectan sitios estatales (Figura 3).

Recientes investigaciones han permitido registrar otros asentamientos de posible factura estatal en cercanías de Tacuil, en dirección noroeste, hacia el abra del Cerro Blanco donde se localizaron 


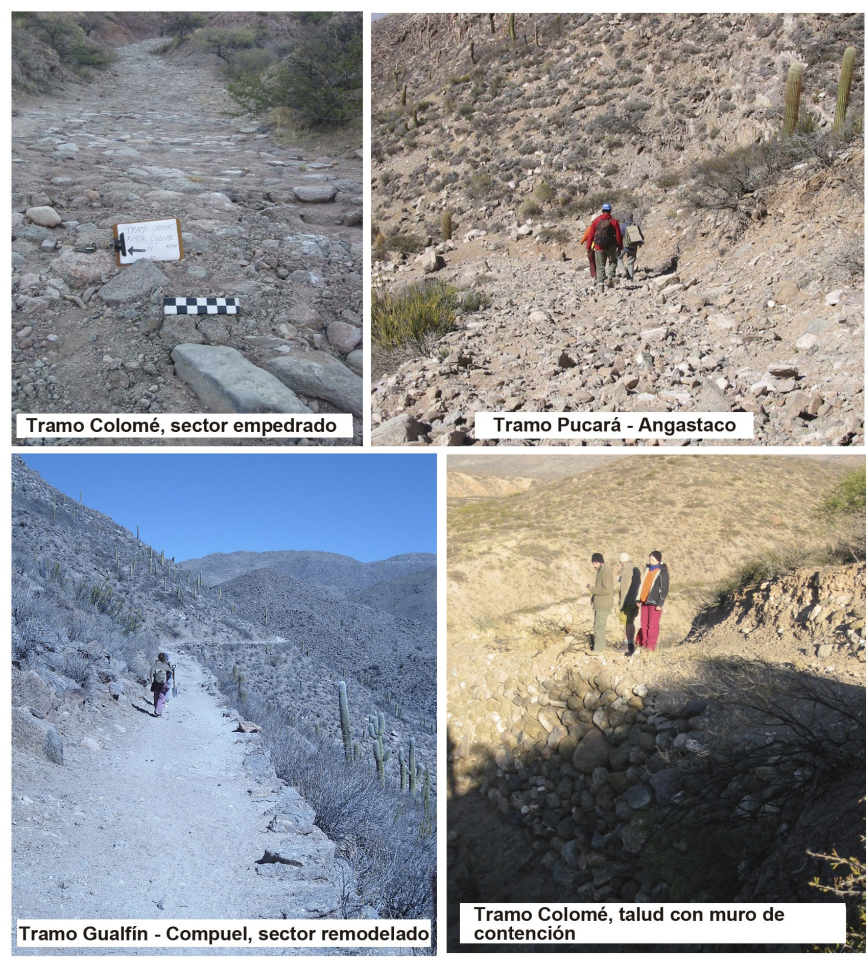

Figura 3. Tramos de caminos que conectan sitios incas en la zona bajo estudio (modificado de Villegas 2014).

Road sections connecting Inca sites in the area under study (modified of Villegas (2014).

cinco sitios en el paraje denominado La Hoyada (La Hoyada 1 a 4 y Rodeotambo) y tramos de vialidad inca (Williams 2018). La Hoyada 3 es un sitio de aproximadamente $14 \mathrm{ha}$, posiblemente agrícola con un pequeño núcleo habitacional ubicado en la parte meridional inferior del sitio. La alfarería presente permitiría asignar una ocupación durante el PDR (Lane 2017). En La Hoyada 4 se registra un tramo de camino que cambia de dirección en varios tramos siguiendo hacia las tierras altas y al Paso de Cerro Blanco (4.549 msm) en la puna. El camino se eleva entre dos ríos secos donde se encuentran dos pequeñas estructuras rectangulares las cuales han sido interpretadas como un posible Chasquiwasi (Lane 2017) (Figura 4).

Se han reconocido nuevos tramos de camino desde Tacuil hacia el sudoeste, pasando por la localidad de Barrancas, en dirección al Abra del Cerro Gordo (4.820 msm) y la puna de Catamarca (Antofagasta de la Sierra), donde registramos el alero Huaicohuasi, a $3.625 \mathrm{msm}$, de $25 \mathrm{~m}$ de boca y $7 \mathrm{~m}$ de altura, con numerosas representaciones visuales, escenas y motivos superpuestos, correspondientes a distintos momento cronológicos como los diseños del tipo "cartuchos" del Formativo, escutiformes y antropomorfos del PDR, personajes con unkus y tocados cefálicos de momentos incas y jinetes del Colonial (Williams 2017).

\section{El Paisaje Agrícola en los Valles Altos del Calchaquí Medio}

Para los sectores altos del Calchaquí, hasta el momento, se han registrado alrededor de más de 400 ha agrícolas y señalado el interés del Estado en la ampliación de las mismas como una estrategia de producción y administración de bienes y servicios a través del dominio del espacio productivo (Williams et al. 2010:203). La extensión y calidad de la infraestructura agrícola de la zona muestra que el área era un importante sector de producción de alimentos antes de la llegada del Estado inca (Williams et al. 2010).

En valles y quebradas altas del Calchaquí medio, en localidades como Tacuil, Mayuco (Punta Peña) y Quebrada Grande se observa como constante la asociación espacial entre campos agrícolas y bloques con grabados de motivos abstractos de líneas serpenteantes unidas a depresiones circulares u ovoidales (cochas o cúpulas) formando parte 

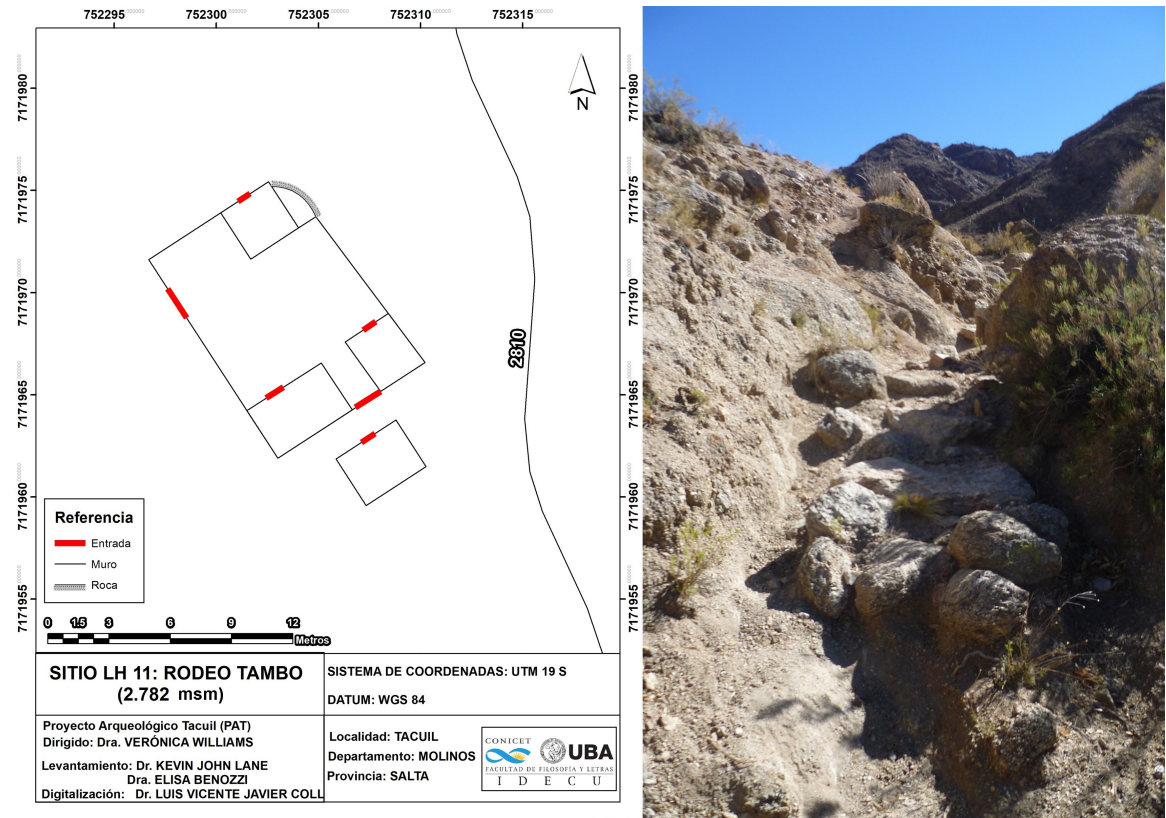

Figura 4. Asentamiento y tramo de camino registrado en la quebrada de La Hoyada (fotografía cedida por K. Lane y E. Benozzi).

Settlement and road section in the La Hoyada gorge (photo courtesy of $K$. Lane and E. Benozzi).

de los muros de las terrazas (Williams et al. 2005). Para los Andes del sur, se han registrado en varias localidades bloques con diseños aterrazados, canales y líneas serpenteantes (maquetas), lo cual ha sido asociado a la delimitación de áreas con distintos derechos de uso por parte de las poblaciones locales (Valenzuela et al. 2004).

Uno de los asentamientos agrícolas analizados y muestreados para fechar es Corralito, que conforma el "Grupo Pucarilla/Corralito" y que se localiza camino a Compuel, sobre la margen izquierda del Río Pucarilla y de uno de sus tributarios, y aproximadamente a $15 \mathrm{~km}$-en línea recta- al sudeste del Pukara de Gualfín (Williams et al. 2010) (Figura 5).

El conjunto Corralito 4 está ubicado sobre una ladera y está formado por una serie de aterrazamientos, despedres perpendiculares a los mismos y estructuras subcirculares internas ubicadas sobre los muros laterales. A diferencia de otros sitios con arquitectura agrícola que estudiamos en el área, aquí hay gran cantidad de cerámica en superficie (estilo Santa María bicolor y con modelado, principalmente). El sitio presenta grandes despedres de rocas de distintos tamaños, que no constituyen un conjunto acomodado. En algunos casos los despedres se presentan paralelos y en otros perpendiculares a la pendiente. Hay también muros dobles en los lados de los andenes, los cuales a veces se abren para incluir posibles unidades residenciales.
No se observan acequias ni existen posibilidades de riego ya que la topografía impediría llevar agua de los cursos cercanos (Williams et al. 2010).

El grupo Corralito 5 está ubicado frente del anterior, en la ladera occidental de un pequeño río tributario del Pucarilla. La regular distribución de los muros y los aterrazamientos, así como la prolijidad y la manufactura estandarizada de sus despedres lo diferencian claramente del resto. Una sola acequia estaría regando este sitio, la cual es cortada en uno de los grandes despedres (Williams et al. 2010).

Los primeros resultados del uso agrícola de los andenes provienen de análisis de microfósiles como polen, microcarbones en relativa escasez y de abundantes gránulos de almidón de tubérculos afines a Solanum sp. y otros aún no identificados (Williams et al. 2010). También hay un número interesante de esferulitas de carbonatos cálcicos (residuos de origen animal asociados a guano). A pesar de estos tentadores indicios de cultivo de papas en los andenes (denotado por los almidones) con uso de fertilizantes (esferulitas) y sin regadío aparente (ausencia de diatomeas y crisofíceas), por ahora no podemos arriesgar un resultado seguro, ya que falta identificar más muestras y realizar los conteos y cruces de datos necesarios. No obstante ello, podemos señalar que Corralito 4 presenta signos de reutilización del espacio, cuya duración y carácter no podemos calibrar ni entender aún. 

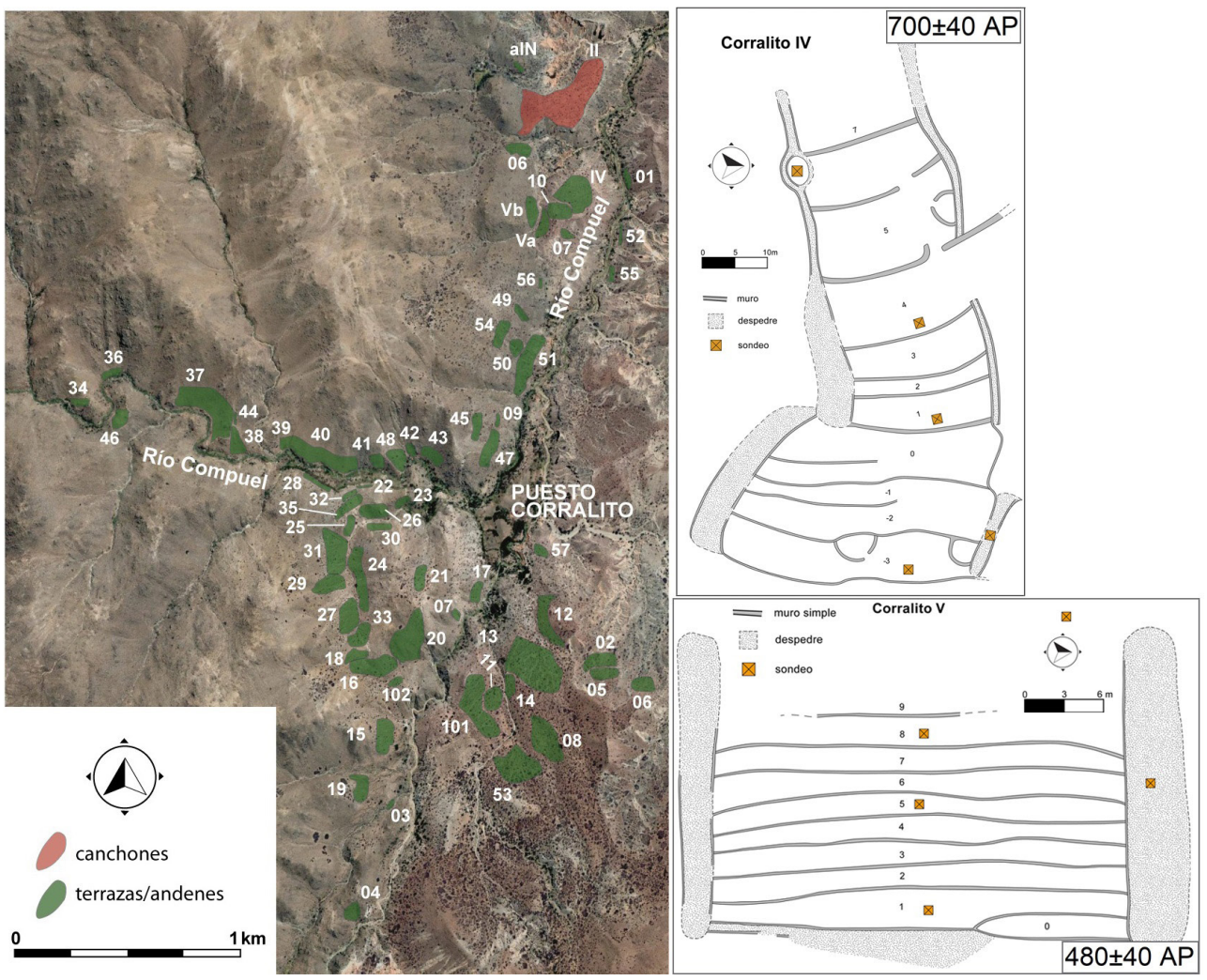

Figura 5. Asentamiento agrícola de Corralito/Pucarilla. Imágenes tomadas de Villegas (2014).

Agricultural settlement of Corralito / Pucarilla. Courtesy by Villegas (2014).

Mientras que Corralito 5, por su datación, sería contemporáneo a la ocupación incaica a lo que sumamos su infraestructura y arquitectura con una verdadera orientación incaica en su diseño (Williams et al. 2010).

\section{Pucarilla y la conjunción entre el paisaje agrícola y funerario}

Hacia fines de 1800, Juan Bautista Ambrosetti realiza las primeras exploraciones en el valle Calchaquí, excavando un contexto funerario en el asentamiento agrícola de Pucarilla, el cual se presenta a los ojos de Ambrosetti con "una larga acequia que desde lo alto debía derramar las aguas del riego, en una serie de plataformas sostenidas por grandes pircas que impedían el desmoronamiento de la tierra, donde los viejos Calchaquíes debieron tener sus plantaciones de maíz, papas y quinoa" (Ambrosetti 1897:303).

Esta descripción nos lleva a considerar que lo que observa Ambrosetti podría tratarse del sector que llamamos Corralito 5, donde se encuentran paños con grandes despedres de manufactura estandarizada que presentan andenes en su interior (Williams et al. 2010).

Dentro de este paisaje, describe una serie de tumbas localizadas sobre el borde de una barranca, de las cuales dos fueron excavadas. Una de ellas contenía el cuerpo de una mujer y la otra era una tumba colectiva (Ambrosetti 1897:303) (Figura 6).

Entre ellas, se destaca especialmente una que contenía:

nueve esqueletos, un puco de alfarería con dibujos de suris (Rhea) y serpientes, una urna, un pinza de depilar de cobre, un cuello de aríbalo, un fragmento de mate con dibujo de serpientes, un fragmento de otro mate con tres personajes dibujados, un mate entero, con once personajes dibujados de frente (Gentile 2013:93).

Actualmente, parte de los materiales de este contexto se encuentran en el depósito del Museo 


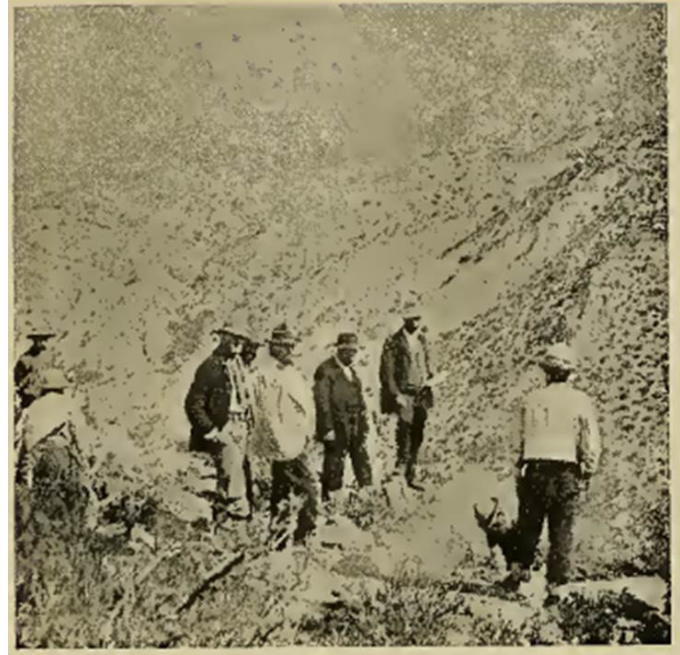

Fig. 23. - Escavando una Tumba



Fig. 24. - Tumba Calchsqui

Figura 6. Excavaciones en tumbas de Pucarilla, Valle Calchaquí. Tomado de Ambrosetti (1987:304).

Excavations in tombs at Pucarilla, Calchaquí Valley. Ambrosetti (1987:304).

Etnográfico "Juan Bautista Ambrosetti” (FFyL, UBA), donde también hemos podido registrar un calzado tipo llanke que presenta similitud con los hallados en el contexto funerario del Quewar, ofrendatorio de altura ubicado en la provincia de Salta, a $6.180 \mathrm{msm}$ (Vitry 2014).

Una de las calabazas pirograbadas contenía representaciones de 11 personajes y la segunda de tres. Se destaca en ambos casos el carácter figurativo de los diseños, pero además el nivel de detalle permite observar distintos tipos de tocados para algunos personajes y atuendos diferenciables también por grupos (Ambrosetti 1899:117) (Figura 7).

\section{Discusiones: Sobre el Concepto de Capacocha y la Marcación Territorial}

"Hasta aquí llega mi capacocha, hasta aquí es mi tierra".

Justicia 413, f. 243r, 250r (Hayashida 2018:7).

La Capacocha se entiende como una ceremonia que podía darse de manera excepcional o cíclica (Duviols 1975). Por ejemplo, en el manuscrito de Huarochirí (citado en Schroedl 2008) un indicio lleva a considerar que la Capacocha tenía lugar regularmente cada año. Diferentes posiciones han llevado a sugerir que esta ceremonia se habría dado como algo excepcional, para combatir una fase de inestabilidad o para reafirmar el orden social (Schroedl 2008).
Por su parte, Cieza de León (1922 [1553], capítulo XXIX) otorga el nombre de Capacocha a dos ceremonias diferentes. Una de ellas correspondería a una reunión de todas las huacas del Tawantinsuyu en el Cusco, para consultarles el futuro, y otra que incluía ritos y sacrificios humanos ofrecidos a las huacas principales. Mientras que Molina (1947) [1573]), relaciona las ceremonias de Capacocha también con las conquistas incas de nuevos territorios.

Al parecer, uno de los objetivos de esta ceremonia habría sido asegurar al soberano una protección contra la adversidad, lo cual implicaba el servicio en ofrendas de todos los santuarios cuyo volumen y calidad dependía de la jerarquía del mismo. Según Rostworowski (2003) esta ceremonia implicaba dos formas: aquella que involucraba el sacrificio humano y otra que se realizaba con sangre líquida transportada en una vasija conducida en un determinado trayecto ritual. Respecto a la segunda, la autora sugiere que, ya sea de sangre de camélidos o humana, correspondía a una costumbre costeña, distinta a la de los niños enterrados o ahogados vivos.

Pero, además, se ha entendido a esta ceremonia como un ritual político que servía para el mantenimiento de la sociedad y del equilibrio, implicando también un control y una apropiación de cultos y santuarios locales (Schroedl 2008:23). Esta mirada permite considerar que la dimensión política de la Capacocha no se restringió exclusivamente a 


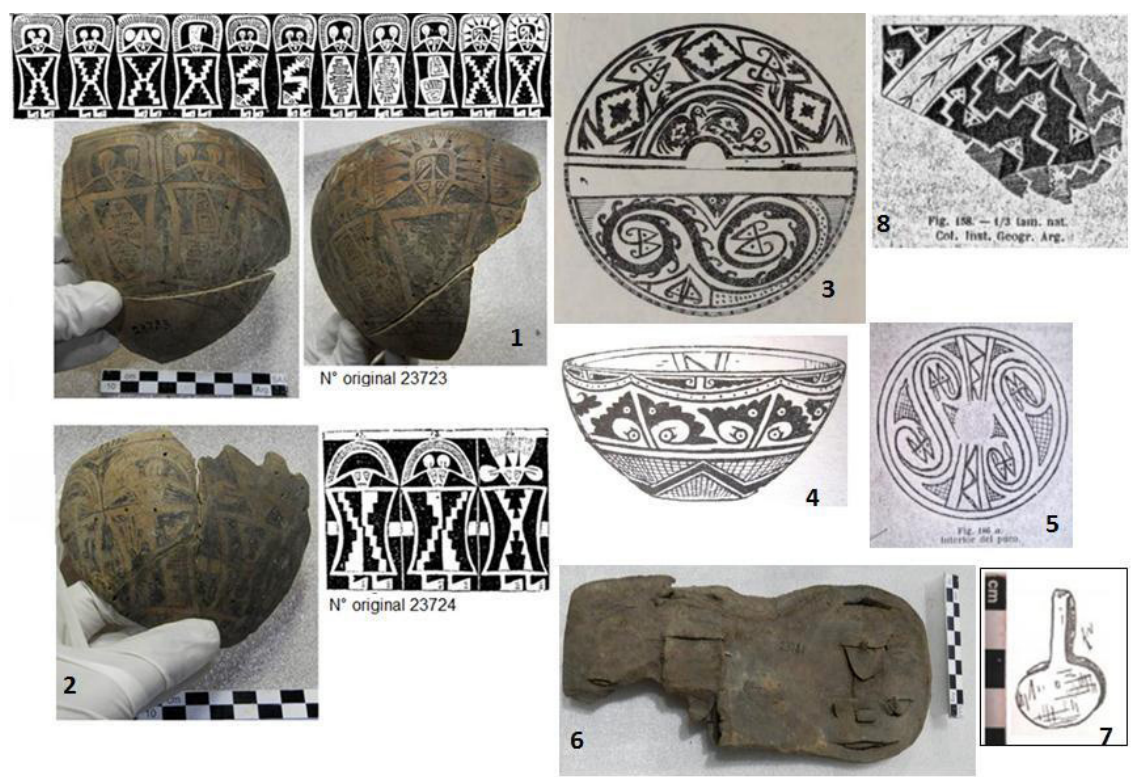

Figura 7. Materiales registrados por Ambrosetti en la tumba de Pucarilla. 1 y 2. Calabazas pirograbadas (Colección Zavaleta. Museo Etnográfico J. B. Ambrosetti. N²3723 y 23724). 3, 4 y 5. Pucos Santa María Valle Arriba mencionados por Ambrosetti (1899). 6. Ushuta (Colección Zavaleta. Museo Etnográfico J. B. Ambrosetti, $\mathrm{N}^{\circ}$ original 23728). 7. Pinza de metal (tomado de Gentile 2013:99). 8. Fragmento de calabaza pirograbada (tomado de Gentile 2013:100).

Materials recorded by Ambrosetti at the tomb of Pucarilla. 1 and 2. Pyrographed gourds (Zavaleta Collection, J. B. Ambrosetti Ethnographic Museum, No. 23723 and 23724). 3, 4 and 5. Santa María Valle Arriba style bowls mentioned by Ambrosetti (1899). 6. Ushuta (Zavaleta Collection, Ethnographic Museum J. Ambrosetti, original $N^{\circ} 23728$ ). 7. Metal clamp (taken from Gentile 2013:99). 8. Fragment of pyrographed gourd (taken from Gentile 2013:100).

favor del inca, sino que se trataba de una negociación en la que jugaban también los intereses de los curacas locales (Schroedl 2008).

Si tomamos en cuenta lo mencionado en párrafos anteriores, nos preguntamos ¿Se pudo haber ejecutado una Capacocha para afianzar, marcar y delimitar el dominio inca en las tierras anexadas al Estado en el Valle Calchaquí? Refiriéndonos al dato que la Capacocha costeña determinaba un deslinde territorial traemos a discusión reflexiones de Gentile (2013), Hayashida (2018) y Rostworowski (2003) sobre un litigio de tierras en 1550 , por los cocales de Quivi en la cuenca del Río Chillón, Perú. Aquí se refiere a la Capacocha como un hito fronterizo y se mencionan algunas materialidades y sujetos que intervenían en dicha ceremonia.

En este caso la Capacocha presentaba un sentido para delimitar espacios y demarcar los linderos de las conquistas cusqueñas. Las delegaciones que salían del Cusco llevaban la ofrenda que consistía en una ollita o un mate lleno de sangre de camélidos, chaquiras molidas y otras cosas, la cual era transportada por los habitantes de cada región, que la entregaban a los vecinos una vez que llegaban a sus límites territoriales
(Rostworowski 2003). Aquí se realizaban ofrendas de ganado y la sangre se repartía en mates de todas las personas que participarían de la siguiente etapa de la ceremonia (Rostworowski 1977:24; AGI 413 f.180).

En un trabajo reciente Hayashida (2018) analiza las incorporaciones de tierras a la esfera estatal y la relación con la ceremonia de Capacocha a partir de un caso mencionado por Hernández Príncipe (1923 [1622] citado en Hayashida 2018:7) y Zuidema (1977 citado en Hayashida 2018:7), donde señala que la "qhapaq hucha tenía el propósito adicional de definir y sacralizar los reclamos del inca sobre tierras de forma que favorecía a ciertos grupos y privaba a otros" (Hayashida 2018:6). Mediante este relato, la autora remarca el papel político que tuvo la Capacocha, integrando nuevos espacios y personas a la esfera estatal y también reorientando los paisajes locales, rituales y productivos, generando cambios en la estructura local de las autoridades, favoreciendo a líderes locales y estableciendo lazos de reciprocidad con el estado, con el propósito de definir y sacralizar los reclamos del Estado inca sobre tierras. 
Para el NOA, los contextos como Llullaillaco y Aconcagua, entre otros, permiten remarcar la importancia del sustrato extra-cuzqueño en las ceremonias de las montañas, dejando abierta la posibilidad de comprender la dinámica interétnica desplegada en relación a la capacocha, y discuten la preeminencia incaica sobre origen, destino, contenido y forma de las ceremonias en las montañas (Mignone 2009:9).

Por otro lado, existen trabajos que ayudan a entender a la Capacocha como una ceremonia ritual que presentó una variedad de espacios, no solo vinculada al ofrecimiento de niños y niñas a las cumbres sagradas (Gibaja Oviedo et al. 2014). Un contexto interesante es el del Cerro Esmeralda, en la costa de Iquique, Chile, donde la presencia de minas de plata de Huantajaya y de "islas de guano" motivó la instalación de un santuario interpretado como una clara forma de poder de corte ideológico, donde el Estado sacralizó el lugar con miras a mostrar y defender su posición sin tener que instalar avanzadas burocráticas o militares de mayor costo de mantención (Checura 1977).

Para el NOA, por ejemplo, Patané Aráoz (2015) analiza el caso de Niño Muerto, en las Salinas Grandes, puna de Jujuy, y sugiere que esta ceremonia podía implicar una variabilidad espacial no solo exclusiva a las cimas de montañas (el remarcado es nuestro).

El caso de las tumbas de Pucarilla permite considerar, a manera de hipótesis, el reclamo y anexión de espacios y sujetos a la esfera política inca. El papel de los objetos que formaron parte de este contexto ha dado lugar a una serie de interpretaciones que sustentan esta hipótesis.

El hallazgo de calabazas pirograbadas, una de ellas con diseños zoomorfos y dos con personajes antropomorfos con uncus, peinados y tocados cefálicos, ha llevado a Gentile (2013:103) a señalar la representación de a pares de lo que podrían ser los curacas de los ayllus. Estas representaciones, según la autora, serían un elemento que podría indicar la participación de estos sujetos en una ceremonia de Capacocha y en procesiones de diferentes comitivas. Interpretando, de esta manera, que dicho contexto podría haber sido parte de un mecanismo oficiado por el estado para censar a la población local que se integraría a la esfera incaica, delimitar fronteras y para ejercer control sobre los diferentes grupos étnicos (Gentile 2013).

Volviendo a la materialidad, los mates con dibujos de la comitiva hallados en la tumba de Pucarilla, según Gentile, podrían indicar que en ese punto geográfico se intentó "frenar el avance de una frontera, y que esa parte de la comitiva más los mates con las ofrendas se transformaron en el nuevo hito fronterizo, una tumba en una ladera" (Gentile 2013:109). Hoy sabemos que esos personajes semejan a los representados en las miniaturas de metal o mullu, personajes ataviados con ropa tejida, que acompañaron las Capacochas de Aconcagua y Llullaillaco, y también algún petroglifo en la ruta de dichas procesiones (Bárcena 1989; Ceruti 2003; entre otros).

Este tipo de objetos y su decoración con diseños antropomorfos también han sido registrados en calabazas de Calama, San Pedro de Atacama, Chiu Chiu y Lasana en el Norte de Chile (Berenguer 2004); en fragmentos hallados en Alero Los Viscos, Valle del Bolsón, Catamarca (Ávila y Puente 2008); en la finca Pucara, en el Valle Calchaquí Medio (Villegas 2014), en Payogastilla (Vasvari 2014) y en piezas de la colección Vittone procedente de la región de Antofagasta de la Sierra, puna de Catamarca depositados en el Museo de Antropología de Salta (Mamani 2007).

En particular, queremos mencionar los contextos funerarios del PDR Inca de Payogastilla y Corralito (ambos en la localidad de San Carlos, al sur de Molinos), que presentan acompañamientos mortuorios de vasijas de estilo Santa María e Inca Provincial. En Pucarilla se hallaron también fragmentos de calabazas pirograbadas con diseños antropomorfos (Vasvari 2014) y en Corralito una pieza con representaciones de una serpiente bicéfala (Castellanos 2017).

Retomando el concepto de la Capacocha de sangre, las fuentes señalan que en los puntos fronterizos se realizaban ofrendas de llamas del ganado del inca, cuya sangre se repartía en los mates de todas las personas que participarían de la siguiente etapa de la procesión. Como durante este trayecto se iban revalidando las fronteras internas del Tawantinsuyu, los jefes locales vigilaban su paso ya que tanto un orejón, un capac ucha camayoc o algún runa portador local de la ofrenda podían resultar muertos al tratar, alguno de ellos, de remover o conservar los mojones en sus sitios (Rostworowski 1977:24; AGI 413 f.180). El deslinde o "amojonamiento" de territorios es frecuentemente mencionado en las crónicas hispanas como una de las prácticas políticas distintivas del Tawantinsuyu (Sanhueza 2004).

La posibilidad de que la tumba de Pucarilla representara una Capacocha que tenía como fin realizar una ofrenda a una huaca y censar a la población local (Gentile 2013:108), permite considerar aquí un mecanismo del Estado para delimitar fronteras y ejercer control sobre los diferentes grupos étnicos en este sector del 
sur andino. Esto también habría implicado la incorporación de cultos y santuarios locales a la esfera Inca. Sabemos por trabajos como los de Kosiba (2015), por ejemplo, que la memoria y sus múltiples formas de manifestarse a través de relatos, tiempos, historias compartidas, materialidades, etc., no son exclusivas de los Incas. Y, de la misma manera, que la construcción y (re)significación de memorias por parte del estado tuvo en cuenta los significados y posiciones de las poblaciones y elementos locales.

Entonces, podemos sugerir que, en caso de que la hipótesis de la Capacocha sea adecuada, el paisaje de Pucarilla pasó a formar parte del sistema político Inca por medio de la expansión de áreas agrícolas y a partir de la marcación territorial y simbólica por las tumbas. De ser así, es importante tener en cuenta la agencia de las poblaciones locales ante el despliegue de estrategias de anexión a la política Inca. Sabemos que el sitio agrícola de Corralito 4 puede adscribirse por el fechado $\mathrm{C} 14$ al periodo PDR o PIT, es decir que este asentamiento estaba en funcionamiento al momento de la expansión Inca en la zona. La presencia de tumbas hacia el interior de las áreas agrícolas no es un dato menor: ¿quizás los ancestros formaron parte de este paisaje agrícola como protectores o tal vez propiciando la fertilidad de los campos?

Si a ello sumamos la propuesta de Gentile de considerar al contexto de Pucarilla como un tipo de capacocha (Gentile 2013:108) podemos sugerir, a manera de hipótesis, que las quebradas altas fueron incorporadas al sistema administrativo y político estatal. Ya sea como área con gran potencial agrícola, como una entrada o puerta que permitía el ingreso al piso de puna donde se localizan montañas que albergan apus y menas metalíferas, o como un espacio con mano de obra especializada, este valle pudo haber generado un importante interés por parte de los incas.

Esfundamental también entendersulocalización como parte de una interacción a una escala mucho más grande, que integra los valles calchaquíes con la actual puna salteña y catamarqueña y, a un nivel más amplio, brinda posibilidad de articular con el norte de Chile y valles como del Cajón y Hualfín en la actual provincia de Catamarca. En este sistema, Compuel sería la puerta o punku desde los valles a los santuarios y ofrendatorios de altura de época inca en la puna (Olivera 1991:53; Williams 2015).

\section{Palabras Finales}

Las investigaciones realizadas hasta el momento en el Valle Calchaquí medio han permitido señalar una ocupación estratégica del territorio, donde los asentamientos incaicos se construyeron separados espacialmente de los locales y distribuidos en puntos claves que funcionarían como ejes a nivel de accesibilidad y control. La evidencia presentada nos lleva a sugerir que la ocupación incaica en los valles y quebradas altas del Calchaquí medio es mucho más intensa y variable de lo que hasta el momento se había sugerido.

Bajo este marco, los caminos se presentan como elementos que conectan y articulan una lógica política y social del Tawantinsuyu, y que contienen "estructuras cargadas de significado que pudieron comportarse como elementos polisémicos, respondiendo a distintos significados o funcionalidades según el contexto y las características con que se presentaran" (Sanhueza 2004:493).

El caso abordado en este trabajo permite plantear a las estructuras funerarias como indicadores de marcación y recreadores de vínculos sociales; destacando el papel del espacio funerario y de los muertos en los procesos de legitimidad territorial (Gil García 2008). En este sentido, consideramos los contextos funerarios de Pucarilla, Payogastilla y Corralito (adscriptos cronológicamente al PDR e Inca) como marcadores territoriales e indicadores de anexión a la política inca. Destacamos, asimismo, el caso de Pucarilla donde la hipótesis que lleva a considerarlo como un contexto de Capacocha sugiere nuevas interpretaciones de orden político, administrativo y territorial; aunque, no debemos dejar de lado también las implicancias simbólicas que pudo haber generado.

La posibilidad del despliegue de una ceremonia ritual utilizada como una práctica demarcatoria de territorios y de expansión de una lógica política sobre un espacio, permite también ampliar nuestra mirada sobre el concepto de Capacocha. Si bien esta es una propuesta, abre el panorama para pensar sobre las estrategias desarrolladas y sobre el papel de las poblaciones locales en las mismas.

En general los Imperios antiguos expanden sus dominios a través de una astuta mezcla de diplomacia, incentivos y fuerza. La expansión inca ocurrió, en algunos casos, bajo un sistema de administración efectivo, lo que significó que las poblaciones locales fueron integradas a las estructuras políticas, económicas e ideológicas del Inca. En este proceso las comunidades vivieron la tensión de aceptar las políticas del Estado, ya fuera por adhesión voluntaria o por imposición estatal debido a circunstancias de resistencia social. En otros casos, aunque disponemos de elementos visibles arqueológicamente sutiles o menos 
evidentes, cierto tipo de mecanismos ideológicos pudieron suceder.

La información arqueológica proveniente de las cuencas al oeste del Río Calchaquí para los siglos XI al XVI da cuenta de una clara continuidad en la ocupación de los espacios y una apropiación y uso de lugares rituales y de producción de alimentos. Los asentamientos incas, diferenciados por su calidad constructiva, forma de las estructuras y materialidades de los de momentos anteriores, no se encuentran directamente asociados a las áreas agrícolas. Esto, sumado a que los asentamientos preincaicos no parecen haber mantenido una gran cantidad de población local, podría estar indicando que el estado invirtió energía en ampliar las áreas agrícolas como una estrategia de producción y administración de bienes y servicios a través del dominio del espacio productivo.

Agradecimientos: A los organizadores del Taller Qhapaq Ñan II por su invitación a publicar. A los pobladores de las Comunidades originarias de Base Territorial Tacuil y Gualfín, a las familias Dávalos (Tacuil) y Bonner (Gualfín). A nuestros compañeros de trabajo y a quienes participaron de las diferentes tareas en campo. A Paula Villegas y Luis Coll por ayudar en la edición del manuscrito y de las imágenes. Las investigaciones fueron financiadas por la Agencia Nacional de Promoción Científica y Tecnológica de la Argentina, por el Consejo Nacional de Investigaciones Científicas y Técnicas y por WennerGren. A los evaluadores de un primer manuscrito, por las sugerencias que ayudaron a mejorarlo.

\section{Referencias Citadas}

Acuto, F. 1999. Paisajes cambiantes: la dominación Inka en el valle Calchaquí Norte (Argentina). Revista do Museu de Arqueologia e Etnologia. Suplemento 3:143-157.

Acuto, F. 2011. Encuentros coloniales, heterodoxia y ortodoxia en el valle Calchaquí Norte bajo el dominio inka. Estudios Atacameños 42:5-32.

Albeck, M.E. 2016. Producción y lógica de la red vial incaica en el extremo septentrional del NOA. Arqueología 22 (1):61-79.

Ambrosetti, J.B. 1897. Por el Valle Calchaquí. Anales de la Sociedad Científica Argentina, Entrega V, Tomo XVIL: 290-305.

Ambrosetti, J.B. 1899. Notas de Arqueología Calchaquí (Continuación). Boletín del Instituto Geográfico Argentino 20:162-187.

Aschero, C., A. Martel y S. López Campeny 2006. Tramas en la Piedra: Rectángulos con Diseños Geométricos en Antofagasta de la Sierra (Puna Meridional Argentina). En Tramas en la Piedra. Producción y Usos del Arte Rupestre, editado por D. Fiore y M. Podestá, pp. 141-156. AINA, WAC y Sociedad Argentina de Antropología, Buenos Aires.

Ávila, F. y V. Puente 2008 ¿Circulación de símbolos? Calabazas pirograbadas en el Tardío. La Zaranda de Ideas 4:109-118.

Baldini, L. 2003. Proyecto arqueología del Valle Calchaquí central (Salta, Argentina). Síntesis y perspectivas. Anales Nueva Época 6:219-239.

Baldini, L. y V. Villamayor 2007. Espacios productivos en la cuenca del río Molinos (Valle Calchaquí, Salta). Cuadernos FHyCS - UNJu $32: 35-51$

Bárcena, R. 1989. La Arqueología Prehistórica del centrooeste argentino. Xama 6-11:9-60.

Bensom, T. 2010. Inka sacrifice and the mummy of Salinas Grandes. Latin American Antiquity 21 (4):399-422.

Berenguer, J. 2001. Couvre-chefs, identité et interaction dans le désert chilien, avant et après la chute de Tiahuanaco. Dossiers de l'Archeologie 262:66-77.
Berenguer, J. 2004. Cinco milenios de arte rupestre en los Andes atacameños: imágenes para lo humano, imágenes para lo divino. Boletín del Museo Chileno de Arte Precolombino 9:75-108.

Castellanos, M.C. 2017. Territorialidades, Interacciones y Materialidades en las Quebradas Altas del Calchaquí Medio (Salta), durante los Siglos XI a XVII. Tesis Doctoral Inédita. Facultad de Filosofía y Humanidades, Universidad Nacional de Córdoba, Córdoba.

Ceruti, C. 2003. Llullaillaco: Sacrificios y Ofrendas en un Santuario Inca de Alta Montaña. Instituto de Investigaciones de Alta Montaña, Universidad Católica de Salta, Salta.

Checura, J. 1977. Funeraria incaica en el Cerro Esmeralda Iquique I Región. Estudios Atacameños 5:127-144.

Cieza de León, P. 1922 [1553]. La Crónica del Perú. Editorial Calpe Madrid.

D'Altroy, T. 2003. Los Incas. Ariel, Barcelona.

D'Altroy, T., A.M. Lorandi, V. Williams, M. Calderari, C. Hastorf, E. De Marrais y M. Hagstrum 2000. Inka rule in the Northern Calchaquí Valley, Argentina. Journal of Field Archaeolgy 27:1-26.

de Hoyos, M. 2011. Guerreros calchaquíes en tiempos del Tawantinsuyu. Entre la violencia y la diplomacia. En Resistencias, Conflictos y Negociaciones. El Valle Calchaquí desde el Período Prehispánico hasta la Actualidad, primera edición, compilado por L. Rodríguez, pp. 63-92. Ediciones Prohistoria, Rosario.

de Hoyos, M. y V. Williams 2017. Abran kancha...Una variante de recinto perimetral compuesto en el noroeste argentino. Estudios Atacameños 55:109-134.

Duviols, P. 1975. La capacocha. Allpanchis 9:11-57.

Gentile, M. 2013. El censo de los runa: datos y reflexiones sobre los incas en el Collasuyu. Nueva corónica 2 (Julio):91-120.

Gentile, M. 2014. La gobernación de Tucumán c. 1570 Comentarios a la "Relación de los pueblos descubiertos por Gerónimo Luis de Cabrera, gobernador de los Juríes". Revista Cruz de Sur IV (6):11-84.

Gibaja Oviedo, A., G. McEwan, M. Chatfield y V. Andrushko 2014. Informe de las posibles Capacochas del asentamiento 
arqueológico de Choquepujio, Cusco, Perú. Ñawpa Pacha, Journal of Andean Archaeology 34 (2):147-175.

González, A.R.1982. Las provincias incas del antiguo Tucumán. Revista del Museo Nacional 46:317-380.

González, L. 2010. Fuegos sagrados. El taller del sitio 15 de Rincón Chico (Catamarca, Argentina). Boletín del Museo Chileno de Arte Precolombino 15 (1):47-62.

González, L. y M. Tarragó 2004. Producción tecnológica e identidad durante el dominio incaico en el Noroeste argentino. Boletín de Arqueología PUCP 8:191-207.

González, L. y M. Tarragó 2005. Vientos del sur. El valle de Yocavil (Noroeste Argentino) bajo la dominación incaica. Estudios Atacameños 29:67-97.

Hayashida, F. 2018. Fields, sacrifice, farmers and the State in the Inka Provinces. En Technology and the Making of Andean Societies, editado por B. Sillar. University College of London Press, en prensa.

Hyslop, J. 1984. The Inka Road System. Academic Press, Orlando.

Kosiba, S. 2015. Tracing the Inca past. Ritual movement and social memory in the Inca imperial capital. En Perspectives on the Inca, editado por M. Barnes, I. de Castro, J. Flores Espinoza, D. Kurella y K. Noack, pp. 178-205. Linden-Museum, Stuttgart.

Lorandi, A.M. 1988. La resistencia y rebeliones de los diaguitocalchaquí en los siglos XVI y XVII. Revista de Antropología 6:3-17.

Mamani, M. 2007. Estudio de un conjunto de artefactos depositados en el Museo de Antropología de Salta. Análisis de la Colección Vittone. Tesis de Licenciatura en Antropología, Facultad de Humanidades, Universidad Nacional de Salta, Salta.

Mignone, P. 2009. Miniaturas zoomorfas del volcán Llullaillaco y contraste entre régimen estatal y vida comunitaria en la capacocha. Boletín del Museo Chileno de Arte Precolombino 14 (1):55-68.

Molina, C. 1947 [1573]. Ritos y Fábulas de los Incas. Colección Eurindia 14, Editorial Futuro, Buenos Aires.

Mulvany, E. 2003. Control Estatal y Economías Regionales. Cuadernos FHyCS-UNJu 20:173-197.

Nielsen, A.E. y W. Walker 1999. Conquista ritual y dominación política en el Tawantinsuyu: El caso de Los Amarillos (Jujuy, Argentina). En Sed non Satiata. Teoría Social en la Arqueología Latinoamericana Contemporánea, editado por A. Zarankin y F. Acuto, pp. 153-169. Ediciones del Tridente, Buenos Aires.

Olivera, D. 1991. La ocupación inka en la Puna meridional argentina. Comechingonia 9:33-72.

Patané Aráoz, J. 2015. Una capacocha inca en Salinas Grandes (La Poma, Salta). El tupu y el plato del "Niño Muerto"... o ¿de la Niña? Estudios Sociales del NOA 16:153-178.

Raffino, R. 1981. Los Inkas del Kollasuyu. Ramos Americana, La Plata.

Raffino R. y L. Baldini 1983. Sitios arqueológicos del valle Calchaquí medio (Depto. Molinos y San Carlos). Estudios de Arqueología 3-4:6-36.

Rebitsch, M. 1966. Santuarios Indígenas en las Altas Cumbres de La Puna de Atacama. Anales de Arqueología y Etnología 21:53-79.

Rostworowski, M. 1977. Etnia y Sociedad. Costa Peruana Prehispánica. Instituto de Estudios Peruanos, Lima.

Rostworowski, M. 2003. Peregrinaciones y procesiones rituales en los Andes. Journal de la Societé des Américanistes 89 (2):97-123.
Sanhueza, C. 2004. Medir, amojonar, repartir: territorialidades y prácticas demarcatorias en el camino incaico de Atacama (II región, Chile). Chungara Revista de Antropología Chilena 36 (2):483-494.

Santoro, C., V. Williams, D. Valenzuela, A. Romero y V. Standen 2010. An archaeological perspective on the Inka Provincial administration of the South-Central Andes. En Distant Provinces in the Inka Empire: Toward a Deeper Understanding of Inka Imperialism, editado por M. Malpass y S. Alconini, pp. 44-74. University of Iowa Press, Iowa.

Schroedl, A. 2008. La Capacocha como ritual político. Negociaciones en torno al poder entre Cuzco y los curacas. Bulletin de l'Institut Français d'Études Andines 37 (1):19-27.

Valenzuela, D., C. Santoro y A. Romero 2004. Arte rupestre en asentamientos del período tardío en los valles de Lluta y Azapa, norte de Chile. Chungara Revista de Antropología Chilena 36 (2):421-437.

Vasvári, V. 2014. Evidencias de Ocupación Incaica en Payogastilla. Sector Sur del Valle Calchaquí. Tesis de Licenciatura en Antropología. Facultad de Humanidades, Universidad Nacional de Salta, Salta.

Villegas, M.P. 2014. Del Valle a la Puna: Articulación Social y Económica entre los Poblados Prehispánicos Tardíos y los Asentamientos Inkas en la Quebrada de Angastaco (Valle Calchaquí Medio, Salta). Tesis Doctoral inédita, Facultad de Filosofía y Letras, Universidad de Buenos Aires, Buenos Aires.

Vitry, C. 2000. Aportes para el Estudio de Caminos Incaicos. Tramo Morohuasi-Incahuasi. Salta, Argentina. Editorial Goica, Salta.

Vitry, C. 2014. Los calzados utilizados por los Incas para las altas montañas. Haucaypata. Investigaciones arqueológicas del Tahuantinsuyo 8:91-109.

Vitry, C. 2017. El rol del qhapaq ñan y los apus en la expansión del Tawantinsuyu. Boletín del Museo Chileno de Arte Precolombino $22(1): 35-49$.

Williams, V. 2004. Poder estatal y cultura material en el Kollasuyu. Boletín de Arqueología PUCP 8:209-245.

Williams, V. 2015. Formaciones sociales en el noroeste argentino. Variabilidad prehispánica en el surandino durante el Periodo de Desarrollos Regionales y el estado Inca. Haucaypata, Investigaciones Arqueológicas en el Tahuantinsuyu 4 (9):62-76.

Williams, V. 2017. Informe de actividades de campo realizadas en la localidad de Tacuil, Molinos, Salta. Presentado en el Museo de Antropología de Salta.

Williams, V. 2018. Informe de actividades de campo realizadas en las localidades de Tacuil y Gualfín, departamento Molinos, Salta. Presentado en el Museo de Antropología de Salta.

Williams, V., A. Korstanje, P. Cuenya y P. Villegas 2010. La dimensión social en la producción agrícola en un sector del Valle Calchaquí medio. En Arqueología de la Agricultura. Casos de Estudio en la Región Andina Argentina, editado por A. Korstanje y M. Quesada, pp. 178-207. Ediciones Magna, Tucumán.

Williams, V., C. Santoro, A. Romero, J. Gordillo, D. Valenzuela y V. Standen 2009. Dominación Inca en los Valles Occidentales (Sur del Perú y Norte de Chile) y el Noroeste Argentino. Andes 7:615-654.

Williams, V. y P. Villegas 2013. Colonización estatal en las cuencas de Angastaco-Molinos (Salta, Argentina). En Al Borde del Imperio. Paisajes Sociales, Materialidad y Memoria en Áreas Periféricas del Noroeste Argentino, compilado por V. Williams y B. Cremonte, pp. 221-252. Publicaciones de la SAA, Buenos Aires.

Williams, V. y P. Villegas 2017. Rutas y senderos prehispánicos como paisajes. Las quebradas altas del valle calchaquí medio (Salta). Boletín del Museo Chileno de Arte Precolombino 22 (1):71-94. 
Williams, V., M.P. Villegas, M.S. Gheggi y M.G. Chaparro 2005. Hospitalidad e intercambio en los valles mesotermales del Noroeste Argentino. Boletín de Arqueología de la PUCP 9:335-373

\section{Notas}

${ }^{1}$ Donde se registraron estructuras de planta rectangular y circular y se extrajeron hachas de piedra y miniaturas de camélido confeccionadas con Spondylus, dos figurinas femeninas envueltas en finos tejidos y tocados de plumas. Como parte del conjunto de textiles se mencionan tres unkus, una túnica, una honda, dos fajas y dos topus de plata (Rebitsch 1966).

2 Se trata de estructuras rectangulares con divisiones cuadrangulares internas. Este tipo de arquitectura en el Noroeste Argentino se ubica entre los 2.200 y $3.700 \mathrm{msm}$, en espacios asociados a cursos de agua, tienen una longitud entre 70 y los $270 \mathrm{~m}$, y un ancho que varia entre $10 \mathrm{~m}$ (para estructuras simples) y $60 \mathrm{~m}$ (estructuras triples) (de Hoyos y Williams 2017:130).

${ }^{3}$ Asentamiento inca localizado entre Pukara y Tambo de Angastaco (sobre fondo de valle) y Compuel (en puna).
${ }^{4}$ De este sitio, hacia 1923, procede el cuerpo de una niña y parte del ajuar que la acompañaba. Esto ha llevado a sugerir que se estaría ante un posible contexto de Capacocha, al igual que otros hallados en el NOA, como Niño Muerto en Salinas Grandes (Bensom 2010; Patané Aráoz 2015).

${ }^{5}$ Las representaciones denominadas como cartuchos fueron descritos como diseños geométricos grabados, cuya forma puede ser un rectángulo de contorno lineal cerrado, aunque en algunos casos aparece abierto o con ausencia de uno de los lados cortos. Este motivo ha sido registrado entre determinadas cotas altitudinales ( 3.500 a $3.800 \mathrm{msm}$ ), en espacios con potencial desarrollo agrícola y eventos cronológicamente posteriores a ca. 2000 años AP y anteriores a ca. 500 años AP (Aschero et al. 2006).

${ }^{6}$ Esta pieza forma parte de la colección Teruel, la cual se encuentra actualmente en el depósito del Museo de Arqueología de Alta Montaña de Salta. 